\title{
Improved model of Advanced Heavy Water Reactor(AHWR)for Control studies
}

\author{
Girish Gokul ${ }^{1}$, Sreyas Rajgopal Shimjith ${ }^{2}$, and Bijnan Bandyopadhyay ${ }^{3}$ \\ ${ }^{1}$ Systems and Control Engineering,Indian Institute of Technology (Bombay),Mumbai-400 076 India \\ ${ }^{2}$ Bhabha Atomic Research Centre, Trombay, Mumbai-400 085, India \\ ${ }^{3}$ Systems and Control Engineering, Indian Institute of Technology (Bombay),Mumbai-400 076 India
}

\begin{abstract}
This paper presents a modified version of coupled neutronics - thermal hydraulics model of Advanced Heavy Water Reactor (AHWR) for control studies. Earlier reported models assume, for the sake of simplicity, that the steam drum level and pressure are being strictly regulated at their respective set points, thereby neglecting these dynamics. However, such models are not suitable for analysis / controller design for the normal mode (load following mode) of operation of AHWR wherein the demand power setpoint is adjusted with respect to fluctuations in steam pressure. The work reported in this paper bridges this gap by including the steam drum pressure and level dynamics in the model. This leads to a model suitable for investigating control related aspects of all operational modes of the reactor. Efficacy of the proposed model is demonstrated through nonlinear simulations.
\end{abstract}

Keywords - AHWR, Thermal Hydraulic , Neutronics, Boiler, Control

\section{Introduction}

The Advanced Heavy Water Reactor(AHWR) is a 920 MW (thermal)nuclear power plant designed to facilitate the timely development of Thorium based technologies for the future. Several innovative passive safety features have been incorporated into this heavy water moderated, boiling light water cooled, natural circulation reactor [1]. Natural circulation of two phase coolant, to remove thermal energy from the vertical core, large physical dimensions of core and the resultant possibility of 'flux tilt' make it imperative to develop a mathematical model of AHWR from a control engineering perspective. Neutronic as well as thermal hydraulic aspects of AHWR modelling have been elaborated in [2-5] and a model with 90 state variables has been derived under the assumption that pressure and water volume in steam drum are strictly controlled. Earlier reported models assume, for the sake of simplicity, that the steam drum level and pressure are being strictly regulated at their respective set points, thereby neglecting these dynamics. However, such models are not suitable for analysis / controller design for the normal mode (load following mode) of operation of AHWR wherein the demand power setpoint is adjusted with respect to fluctuations in steam pressure. The work reported in this paper bridges this gap by including the steam drum pressure and level dynamics in the model.

The mathematical model of the reactor core aims to estimate the spatial neutron flux and power distribution under steady state as well as transient operating conditions. Nodal methods, wherein the reactor core is divided into relatively larger mesh boxes (nodes), have been successfully employed to capture the dynamics of reactor cores $[6,7]$. It has been shown that in the case of AHWR, a subdivision into 17 nodes is optimal for capturing the essential linear system properties and steady state power distribution. Consideration of the thermal hydraulic aspects owing to the usage of boiling light water was brought out in [1]. The thermal hydraulic modelling aspect of steam drums has been covered in [8] wherein a simple fourth order nonlinear model has been derived from first principles. A preliminary 9 node non linear model of AHWR was introduced in [2] based on a similar approach of considering mass and energy balances of steam drum and riser section. A refined nodal model was presented in [3]. In [4] the nodal model was clubbed with the thermal hydraulic model and linearized around the full power operating point and the spatial stabilization of the reactor core was explored. An alternative thermal hydraulic model clubbed with a point kinetic neutronic model was introduced in $[9,10]$.

The linear model introduced in [4] has been adopted for evaluation and comparision of different control strategies. A resolution of the model into three time scales based on singular perturbation analysis [11] followed by design of a composite controller as well as Fast Output Sampling methods were explored in [12]. In [13] sliding mode control based on a two time scale approach has been applied to the linear model introduced in [4]. Periodic Output Feedback Technique was applied to the model in [14]. Model order reduction techniques have been applied to the linearised model of AHWR in [15]. A comparision of the order reduction techniques is also included in the same. 
Table 1. Notations

\begin{tabular}{|llll|}
\hline & Symbols & & Subscripts \\
\hline $\mathrm{Q}$ & Thermal power & $h_{d}$ & Enthalpy \\
$\mathrm{C}$ & Neutron precursor conc. & $\mathrm{I}$ & Iodine \\
$\mathrm{I}$ & Iodine concentration & $\mathrm{Xe}$ & Xenon \\
$\mathrm{Xe}$ & Xenon concentration & $\mathrm{h}$ & Node number \\
$\mathrm{H}$ & \%'in' position of control rods & $\mathrm{d}$ & Downcomer \\
$\rho$ & Reactivity & $\mathrm{f}$ & Feed water \\
$\beta$ & Delayed neutron fraction & $\mathrm{r}$ & Riser \\
$\alpha_{h h}$ & Coupling coefficient & $\mathrm{S}$ & Steam \\
$\lambda$ & Half life & $\mathrm{W}$ & Water \\
$\gamma$ & Fractional fission yield & $\mathrm{c}$ & Vaporization \\
$\Sigma_{f}$ & Fission cross-section & & \\
$\Sigma_{a}$ & Absorption cross-section & & \\
1 & Neutron life time & & \\
$\sigma$ & Microscopic cross-section & & \\
$k_{1}$ to $k_{4}$ & Polynomial fitting coefficients & & \\
$\mathrm{q}$ & Mass flow rate & & \\
$\mathrm{u}$ & Internal energy & & \\
$\mathrm{V}$ & Steam drum volume & & \\
$V_{w}$ & Steam drum water volume & & \\
$V_{C}$ & Channel volume & & \\
$\mathrm{x}$ & Exit mass quality & & \\
$x_{a v g}$ & Average exit mass quality & & \\
$\mathrm{K}$ & Constant for control rods' motion & & \\
\hline
\end{tabular}

The cardinal assumption adopted in [4] was that steam drum pressure and water volume are strictly controlled at their respective set points. In other words, the present model of AHWR with 90 states does not capture the pressure and water volume changes in the steam drum. However, in order to analyze the normal mode of operation of AHWR wherein pressure changes lead to the readjustment of demand set point for reactor power, it is essential to have a model which captures pressure and water volume dynamics. In this paper we include the steam drum pressure and water volume as state variables to extend the nonlinear model and simulate the responses.

The rest of the paper is organised as follows. Section 2 presents an overview of the AHWR model development. Section 3 presents the simulation of non-linear model response. Concluding remarks follow thereafter.

\section{Improved model of the AHWR}

Development of a mathematical model of AHWR comprises development and integration of models of core neutronics, reactivity feedbacks and thermal hydraulics, as described in the subsequent subsections. In this paper, the core neutronics and thermal hydraulic models are adopted from [3] and [2], however, the underlying equations are revisited here for brevity. Thermal hydraulics model is developed from first principles considering the steam drum pressure and level dynamics, and is augmented with the neutronics model.

\subsection{Core Neutronics model}

The AHWR core is divided into 17 nodes, in which the neutronics behaviour is characterized by a multi-point kinetics model with one group of delayed neutron precursors' and coupling between the neighbouring nodes represented using appropriate coupling coefficients. Xenon and Iodine concentrations are also modelled in order to cater for xenon reactivity feedback. The equations describing the core neutronics follow from [3].

$$
\begin{aligned}
\frac{d Q_{h}}{d t} & =\left(\rho_{h}-\beta-\alpha_{h h}\right) \frac{Q_{h}}{l}+\sum_{k=1}^{17} \alpha_{k h} \frac{Q_{k}}{l}+\lambda C_{h} \\
\frac{d C_{h}}{d t} & =\frac{\beta}{l} Q_{h}-\lambda C_{h} \\
\frac{d I_{h}}{d t} & =\gamma_{I} \Sigma_{f h} Q_{h}-\lambda_{I} I_{h} \\
\frac{d X e_{h}}{d t} & =\gamma_{X e} \Sigma_{f h} Q_{h}+\lambda_{I} I_{h}-\left(\lambda_{X e}+\bar{\sigma}_{x h} Q_{h}\right) X e_{h} \\
\frac{d H_{h}}{d t} & =K v_{h}
\end{aligned}
$$

\subsection{Reactivity feedbacks}

The reactivity term $\rho_{h}$ in (1) is expressed as a sum of reactivity feedbacks due to Xenon $\left(\rho_{X e_{h}}\right)$, coolant void fraction $\left(\rho_{x_{h}}\right)$ and regulating rod position $\left(\rho_{H}\right)$ as

$$
\rho_{h}=\rho_{X e_{h}}+\rho_{x_{h}}+\rho_{H}
$$


where reactivity contribution due to Xenon concentration in node $h$ is :

$$
\rho_{X e_{h}}=-\frac{\bar{\sigma}_{X e_{h}} X e_{h}}{\Sigma_{a_{h}}}
$$

The coupling between the neutronic and the thermal hydraulic models is due to nodal power $\left(Q_{h}\right)$, which acts as the input to the riser dynamics, and the reactivity feedback $\left(\rho_{x_{h}}\right)$ due to exit quality of steam, which is given by

$$
\begin{aligned}
\rho_{x_{h}} & =-5 \times 10^{-3}\left(9.2838 x_{h}{ }^{5}-27.7192 x_{h}{ }^{4}\right. \\
& \left.+31.7643 x_{h}{ }^{3}-17.7389 x_{h}{ }^{2}+5.2308 x_{h}+0.0792\right)
\end{aligned}
$$

and the reactivity contributed due to the control rods is

$$
\rho_{H_{h}}= \begin{cases}\left(-10.234 H_{h}+676.203\right) \times 10^{-6}, & \text { if } h=2,4,6,8 \\ 0 & \text { elsewhere }\end{cases}
$$

\subsection{Thermal Hydraulics model}

The thermal hydraulic modelling approach adopted in [3] is adapted from a first principles approach in the lines of [8]. The mass and energy balances for the steam drum are drawn up by dividing the main heat transport loop into the water volume, the steam volume, the complete steam drum, the riser boiling volume section and the complete drum boiler and riser downcomer sections, as shown in fig. 1. State variables chosen to capture the parameters of the drum boiler are water volume inside the steam drum $\left(V_{w}\right)$, pressure $(p)$, exit quality $\left(x_{h}\right)$ for all 17 nodes and downcomer enthalpy $\left(h_{d}\right)$. Table 2 lists the state variables' dynamics that are captured by the associated mass and energy balance equations. The choice of equations would have to be such that the relevant information about all the state variables are captured.

It is assumed that the coolant channels in each node and corresponding risers are represented by equivalent lumped channel and riser, and the enthalpy of subcooled coolant entering each channel is same. It is also assumed that the point of inception of boiling of the coolant in the channel varies according to the power level. The downcomer flow rate is expressed as a polynomial function of the nodal powers. Under assumptions of steady thermal flux and no slip [8], the mass and energy balance equations for individual sections are developed to capture the behaviour of the system.

Average void fraction $\alpha_{h}$ in the node $h$ is related to exit quality $x_{h}$ as :-

$$
\alpha_{h}=\frac{\rho_{w}}{\rho_{w}-\rho_{s}}\left[1-\frac{\rho_{s}}{\left(\rho_{w}-\rho_{s}\right) x_{h}} \log \left(1+\frac{x_{h}\left(\rho_{w}-\rho_{s}\right)}{\rho_{s}}\right)\right]
$$

Mass and Energy balance equations for the riser section are combined to capture the coupling effects of $h_{d}$ and nodal exit quality and also to account for thermal energy utilised in heating up downcomer water to saturation temperature. Mass balance equations for complete Drum

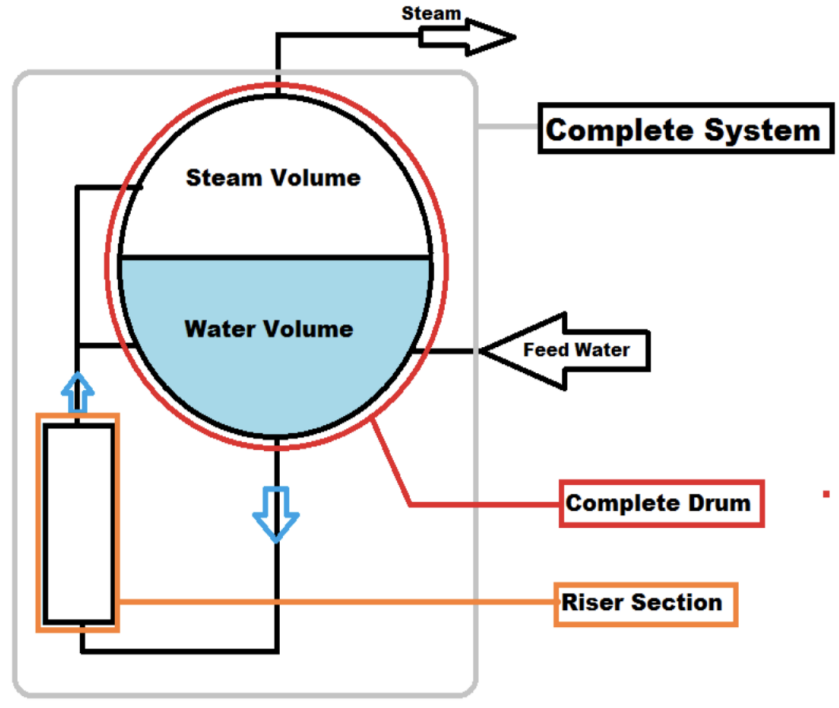

Figure 1. Schematic of main heat transport loop of AHWR

Table 2. State Variable Dynamics

\begin{tabular}{|c|l|l|l|}
\hline Section & \multicolumn{1}{|c|}{ Description } & $\begin{array}{l}\text { Mass } \\
\text { balance }\end{array}$ & $\begin{array}{l}\text { Energy } \\
\text { balance }\end{array}$ \\
\hline $\mathbf{1}$ & $\begin{array}{l}\text { Water volume } \\
\text { in Steam Drum }\end{array}$ & $V_{w}, p$ & $V_{w}, p, h_{d}$ \\
\hline $\mathbf{2}$ & $\begin{array}{l}\text { Steam volume } \\
\text { in Steam Drum }\end{array}$ & $V_{w}, p$ & $V_{w}, p$ \\
\hline $\mathbf{3}$ & $\begin{array}{l}\text { Combined } \\
\text { Steam Drum }\end{array}$ & $V_{w}, p$ & $V_{w}, p, h_{d}$ \\
\hline $\mathbf{4}$ & $\begin{array}{l}\text { Boiling volume } \\
\text { in Riser Section }\end{array}$ & $p, x_{h}$ & $p, x_{h}$ \\
\hline
\end{tabular}

boiler and riser assembly can be drawn up by combining the mass balance equations for Riser section and steam drum section. The resulting equation captures exit quality dynamics and the coupling between the power $\left(Q_{h}\right)$ and the exit quality due to the downcomer flow rate. The choice of the energy balance equation of the complete model is to capture the enthalpy, pressure and water volume dynamics. The final equation can be chosen between the energy balance of water volume or steam volume in steam drum.

\subsubsection{Riser modelling}

The boiling volume in the lumped channel of a node is given by [3]

$$
V_{b_{h}}=V_{C_{h}} \frac{Q_{h}-q_{d_{h}}\left(h_{w}-h_{d}\right)}{Q_{h}}
$$

Mass balance in the boiling volume yields:

$$
q_{d_{h}}-q_{r_{h}}=\frac{d}{d t}\left(\rho_{s} \alpha_{h} V_{b_{h}}+\rho_{w}\left(1-\alpha_{h}\right) V_{b_{h}}\right)
$$


Energy balance in the boiling volume yields:

$$
\begin{aligned}
& {\left[Q_{2_{h}}+q_{d_{h}} h_{w}-q_{r_{h}}\left(x_{h} h_{c}+h_{w}\right)\right]=\frac{d}{d t}\left[\rho_{s} \overline{\alpha_{h}} V_{b_{h}} h_{s}\right.} \\
& \left.\quad+\rho_{w}\left(1-\overline{\alpha_{h}}\right) V_{b_{h}} h_{w}-P V_{b_{h}}\right]
\end{aligned}
$$

Coolant inlet flow rate can be modelled by considering the momentum balance equation, but for the sake of simplicity it is modelled as a polynomial function of the normalised nodal power as [3]

$$
q_{d_{h}}=\left(k_{1}\left(\frac{Q_{h}}{Q_{h_{o}}}\right)^{3}+k_{2}\left(\frac{Q_{h}}{Q_{h_{o}}}\right)^{2}+k_{3}\left(\frac{Q_{h}}{Q_{h_{o}}}\right)+k_{4}\right) q_{d_{h} o}
$$

where $\quad k_{1}=0.2156 \quad ; k_{2}=-0.5998 ; k_{3}=0.48538 \quad$ and $k_{4}=0.8988 . q_{r_{h}}$ is eliminated from equations (11) and (12) to yield

$$
e_{v p_{h}} \frac{d P}{d t}+e_{v x_{h}} \frac{d x_{h}}{d t}=Q_{h}-q_{d_{h}}\left(h_{w}-h_{d}\right)-x_{h} h_{c} q d_{h}
$$

where $e_{v p_{h}}$ and $e_{v x_{h}}$, are given by

$$
\begin{aligned}
e_{v p_{h}} & =\left(\rho_{w} \frac{d h_{w}}{d P}-x_{h} h_{c} \frac{d \rho_{w}}{d P}\right)\left(1-\overline{\alpha_{h}}\right) V_{b_{h}}+\left(\left(1-x_{h}\right) h_{c} \frac{d \rho_{s}}{d P}\right. \\
& \left.+\rho_{s} \frac{d h_{s}}{d P}\right) \overline{\alpha_{h}} V_{b_{h}}+\left(\rho_{s}+\left(\rho_{w}-\rho_{s}\right) x_{h}\right) h_{c} V_{b_{h}} \frac{d \overline{\alpha_{h}}}{d P}-V_{b_{h}} \\
e_{v x_{h}} & =\left(\left(1-x_{h}\right) \rho_{s}+x_{h} \rho_{w}\right) h_{c} V_{b_{h}} \frac{d \overline{\alpha_{h}}}{d x_{h}}
\end{aligned}
$$

\subsubsection{Steam Drum Modelling}

Mass balance equation in the steam drum yields

$$
\left(q_{f}+q_{r}\right)-\left(q_{s}+q_{d}\right)=\frac{d}{d t}\left(\frac{V_{w}\left(\rho_{w}+\rho_{d}\right)}{2}\right)+\frac{d}{d t}\left(\rho_{s} V_{s}\right)
$$

Energy balance equations can be expressed by equating the internal energy increase with the enthalpy increase. The average exit quality, $x_{\text {avg }}$ is replaced here by $x$ for ease of representation.

$$
\begin{aligned}
& \frac{d}{d t}\left(\frac{\left(\rho_{w} u_{w}+\rho_{d} u_{d}\right) V_{w}}{2}\right)+\frac{d}{d t}\left(\rho_{s} V_{s} u_{s}\right)+m_{d} C_{p} \frac{d t_{s}}{d t} \\
& =x q_{r} h_{s}+(1-x) q_{r} h_{w}-q_{d} h_{d}+q_{f} h_{f}-q_{s} h_{s}
\end{aligned}
$$

where

$$
x=\frac{\Sigma_{h=1}^{Z} x_{h} q_{r_{h}}}{\sum_{h=1}^{Z} q_{r_{h}}} ; q_{r}=\Sigma_{h=1}^{Z} q_{r_{h}} ; q_{d}=\Sigma_{h=1}^{Z} q_{d_{h}}
$$

Substitution of internal energy $u\left(=h-\frac{P}{\rho_{d}}\right)$ and $V_{d}\left(=V_{s}+V_{w}\right)$ in the mass and energy balance equations gives

$$
\begin{array}{r}
e_{p v} \frac{d V_{w}}{d t}+e_{p p} \frac{d P}{d t}=-\Sigma_{h=1}^{Z}\left(q_{d_{h}}-q_{r_{h}}\right)+q_{f}-q_{s} \\
e_{x v} \frac{d V_{w}}{d t}+e_{x p} \frac{d P}{d t}+e_{x_{h}} \frac{d h_{d}}{d t}=x q_{r} h_{s}+(1-x) q_{r} h_{w} \\
-q_{d} h_{d}+q_{f} h_{f}-q_{s} h_{s}
\end{array}
$$

where

$$
\begin{aligned}
e_{p v} & =\frac{\rho_{w}+\rho_{d}}{2}-\rho_{s} \\
e_{p p} & =V_{s} \frac{d \rho_{s}}{d P}+\frac{V_{w}}{2} \frac{\rho_{w}+\rho_{d}}{d P} \\
e_{x v} & =\frac{\rho_{w} h_{w}+\rho_{d} h_{d}}{2}-\rho_{s} h_{s} \\
e_{x p} & =\frac{V_{w}}{2}\left(h_{w} \frac{d \rho_{w}}{d P}+\rho_{w} \frac{d h_{w}}{d P}+\rho_{d}\right)+V_{s}\left(h_{s} \frac{d \rho_{s}}{d P}+\rho_{s} \frac{d h_{s}}{d P}\right) \\
& -V_{d}+m_{d} C_{p} \frac{d t_{s}}{d P} \\
e_{x_{h}} & =\frac{V_{w}}{2} \rho_{d}
\end{aligned}
$$

From (11) and (9), we get

$$
q_{d_{h}}-q_{r_{h}}=\bar{e}_{p p h} \frac{d P}{d t}+\bar{e}_{p x h} \frac{d x_{h}}{d t}
$$

where

$$
\begin{aligned}
& \bar{e}_{p p_{h}}=V_{b_{h}}\left(\left(1-\bar{\alpha}_{h}\right) \frac{d \rho_{w}}{d P}+\bar{\alpha}_{h} \frac{d \rho_{s}}{d P}-\left(\rho_{w}-\rho_{s}\right) \frac{d \bar{\alpha}_{h}}{d P}\right) \\
& \bar{e}_{p x_{h}}=-V_{b_{h}}\left(\left(\rho_{w}-\rho_{s}\right) \frac{d \bar{\alpha}_{h}}{d x_{h}}\right)
\end{aligned}
$$

Substituting the values of $\left(q_{d_{h}}-q_{r_{h}}\right)$ in the mass balance equations (15), the equations governing the dynamic model of the steam drum can be obtained as:

$$
\begin{aligned}
& e_{p v} \frac{d V_{w}}{d t}+\bar{e}_{p p} \frac{d P}{d t}+\Sigma_{h=1}^{Z} \bar{e}_{p x_{h}} \frac{d x_{h}}{d t}=q_{f}-q_{s} \\
& e_{x v} \frac{d V_{w}}{d t}+e_{x p} \frac{d P}{d t}= x q_{r} h_{s}+(1-x) q_{r} h_{w}-q_{d} h_{d} \\
&+q_{f} h_{f}-q_{s} h_{s}
\end{aligned}
$$

Energy balance for the water volume inside the steam drum yields

$$
e_{v h} \frac{d V_{w}}{d t}+e_{p h} \frac{d P}{d t}+e_{x h} \frac{d h_{d}}{d t}=(1-x) q_{r} h_{w}-q_{d} h_{d}+q_{f} h_{f}
$$

(21), (22) and (23) constitute the equations governing the steam drum pressure, water volume and downcomer enthalpy dynamics, wherein

$$
\begin{aligned}
\bar{e}_{p p} & =e_{p p}+\Sigma_{h=1}^{Z} \bar{e}_{p p_{h}} \\
e_{v h} & =\frac{\rho_{w} h_{w}}{2}-P+\frac{\rho_{d} h_{d}}{2} \\
e_{p h} & =\frac{\rho_{w} V_{w}}{2} \frac{d h_{w}}{d P}-V_{w}+\frac{h_{d} V_{w}}{2} \frac{d \rho_{d}}{d P}+\frac{h_{w} V_{w}}{2} \frac{d \rho_{w}}{d P} \\
e_{x h} & =\frac{\rho_{d} V_{w}}{2}
\end{aligned}
$$

(21), (22) and (23), along with (14) constitute the nonlinear model of the steam drum and the associated risers and downcomers. 
With this, the complete set of equations governing the nonlinear model of AHWR are summarized as:

$$
\begin{aligned}
\frac{d Q_{h}}{d t} & =\left(\rho_{h}-\beta-\alpha_{h h}\right) \frac{Q_{h}}{l}+\sum_{k=1}^{17} \alpha_{k h} \frac{Q_{k}}{l}+\lambda C_{h} \\
\frac{d C_{h}}{d t} & =\frac{\beta}{l} Q_{h}-\lambda C_{h} \\
\frac{d I_{h}}{d t} & =\gamma_{I} \Sigma_{f h} Q_{h}-\lambda_{I} I_{h} \\
\frac{d X e_{h}}{d t} & =\gamma_{X e} \Sigma_{f h} Q_{h}+\lambda_{I} I_{h}-\left(\lambda_{X e}+\bar{\sigma}_{x h} Q_{h}\right) X e_{h} \\
\frac{d H_{j}}{d t} & =K v_{j}
\end{aligned}
$$

and

$$
\begin{aligned}
& e_{x v} \frac{d V_{w}}{d t}+e_{x p} \frac{d P}{d t}+e_{x_{h}} \frac{d h_{d}}{d t}=x q_{r} h_{s}+(1-x) q_{r} h_{w} \\
& \quad-q_{d} h_{d}+q_{f} h_{f}-q_{s} h_{s} \\
& e_{v p_{h}} \frac{d P}{d t}+e_{v x_{h}} \frac{d x_{h}}{d t}=Q_{h}-q_{d_{h}}\left(h_{w}-h_{d}\right)-x_{h} h_{c} q d_{h} \\
& e_{v h} \frac{d V_{w}}{d t}+e_{p h} \frac{d P}{d t}+e_{x h} \frac{d h_{d}}{d t}=(1-x) q_{r} h_{w}-q_{d} h_{d}+q_{f} h_{f} \\
& e_{p v} \frac{d V_{w}}{d t}+\bar{e}_{p p} \frac{d P}{d t}+\Sigma_{h=1}^{Z} \bar{e}_{p x_{h}} \frac{d x_{h}}{d t}=q_{f}-q_{s}
\end{aligned}
$$

where the $e$ parameters are given by:-

$$
\begin{aligned}
e_{v p_{h}}= & \left(\rho_{w} \frac{d h_{w}}{d P}-x_{h} h_{c} \frac{d \rho_{w}}{d P}\right)\left(1-\overline{\alpha_{h}}\right) V_{b_{h}}+\left(\left(1-x_{h}\right) h_{c}\right. \\
& \left.\frac{d \rho_{s}}{d P}+\rho_{s} \frac{d h_{s}}{d P}\right) \overline{\alpha_{h}} V_{b_{h}} \\
& +\left(\rho_{s}+\left(\rho_{w}-\rho_{s}\right) x_{h}\right) h_{c} V_{b_{h}} \frac{d \overline{\alpha_{h}}}{d P}-V_{b_{h}} \\
e_{v x_{h}}= & \left(\left(1-x_{h}\right) \rho_{s}+x_{h} \rho_{w}\right) h_{c} V_{b_{h}} \frac{d \overline{\alpha_{h}}}{d x_{h}} \\
e_{x v}= & \frac{\rho_{w} h_{w}+\rho_{d} h_{d}}{2}-\rho_{s} h_{s} \\
e_{x p}= & \frac{V_{w}}{2}\left(h_{w} \frac{d \rho_{w}}{d P}+\rho_{w} \frac{d h_{w}}{d P}+\rho_{d} \frac{d h_{d}}{d P}\right) \\
+ & V_{s}\left(h_{s} \frac{d \rho_{s}}{d P}+\rho_{s} \frac{d h_{s}}{d P}\right)-V_{d}+m_{d} C_{p} \frac{d t_{s}}{d P} \\
e_{p v}= & \frac{\rho_{w}+\rho_{d}}{2}-\rho_{s} \\
\bar{e}_{p p}= & e_{p p}+\Sigma_{h=1}^{Z} \bar{e}_{p p_{h}} \\
\bar{e}_{p x_{h}}= & -V_{b_{h}}\left(\left(\rho_{w}-\rho_{s}\right) \frac{d \bar{\alpha}_{h}}{d x_{h}}\right) \\
e_{v h}= & \frac{\rho_{w} h_{w}}{2}-P+\frac{\rho_{d} h_{d}}{2} \\
e_{p h}= & \frac{\rho_{w} V_{w}}{2} \frac{d h_{w}}{d P}-V_{w}+\frac{h_{d} V_{w}}{2} \frac{d \rho_{d}}{d P}+\frac{h_{w} V_{w}}{2} \frac{d \rho_{w}}{d P} \\
e_{x h} V_{w} &
\end{aligned}
$$

\subsubsection{Steady state values}

The equilibrium point of the nonlinear model can be calculated by fixing the values of pressure $(7 \mathrm{MPa})$, power $\left(Q_{h}\right)$ and downcomer flow rate for each node [4],[5]. Steady state value of Riser flow rate can be found directly but that of the state variables as well as feed flow and steam flow rate would require iterative solution of the following set of equations:

$$
\begin{aligned}
x_{h_{\text {avg }}} & =1-\frac{\sum_{h=1}^{17} q_{d_{h}} h_{d}-q_{f} h_{f}}{q_{r} h_{w}} \\
q_{s} & =\sum_{h=1}^{17}\left(x_{h} q_{r_{h}}\right) \\
q_{f} & =q_{s} \\
h_{d} & =\frac{1-x_{h_{a v g}} q_{r} h_{w}+q_{f} h_{f}}{\sum_{h=1}^{17} q_{d_{h}}}
\end{aligned}
$$

\section{Model Simulations}

The nonlinear model is simulated with a time step of 5 milliseconds using a first order Runge Kutta solver. Saturated/subcooled steam/water properties were computed using steam tables as per [16, 17], and the values were generated according to the AHWR specific data as given in [4].

The reactor was initially simulated at full power operating conditions and a $10 \%$ step increase in steam offtake rate was simulated at $50^{\text {th }}$ second of operation. The effect of inclusion of pressure and water volume as state variables on exit mass quality and reactor power is shown in figure 3. Comparision of responses between a thermal hydraulic model and combined neutronics model is presented in figures 4 to 6 to demonstrate the effect of feedback coupling due to void reactivity on the parameters of the thermal hydraulic model. Initially the reactor is assumed to be operating at $50 \%$ full power. At 50 seconds, the steam flow rate was increased by a step rise of $10 \%$ with feed flow being adjusted to maintain same rate as steam offtake rate.

Next, three separate cases of reactor operation at $50 \%$, $80 \%$ and $100 \%$ of full power were considered. After 10 seconds of operation, the steam flow rate is increased by $10 \%$ and the corresponding responses are depicted by figures 7 and 8 . Figures 9 and 10 depict the model response to a step change of $10 \%$ decrease in steam uptake rate.

Subsequently the response of the model is compared with that of a third order thermal hydraulic model of AHWR reported in [9] and [10]. A parallel is drawn with responses for drum boiler dynamics presented in [8]. Figures 11 and 12 depict the corresponding variations in different parameters.

\subsection{Results and Discussions}

The coupling of the thermal hydraulic model with the neutronics model introduces the effect due to negative coefficient of void reactivity feedback of the neutronic reactions and is observed in figure 2.Steam quality changes are sensitive to changes in pressure. While the earlier model had assumed pressure to be constant, inclusion of pressure as a state variable for this model ensures power dynamics are captured more accurately as depicted in 3 . The effect 


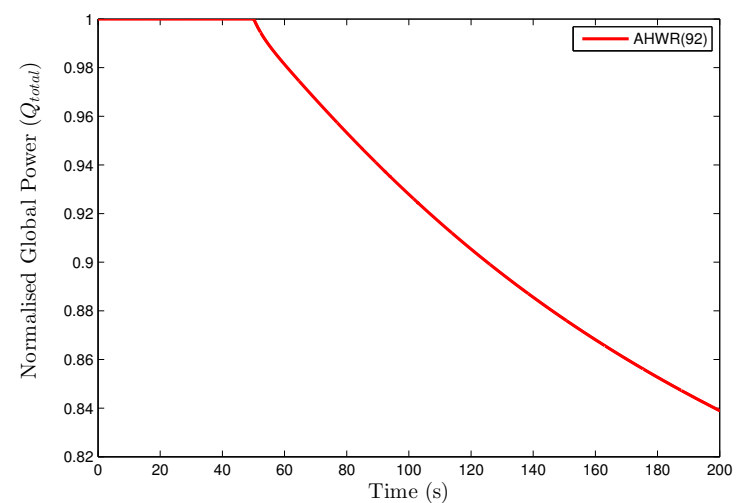

Figure 2. Effect of Exit Quality on Global Power

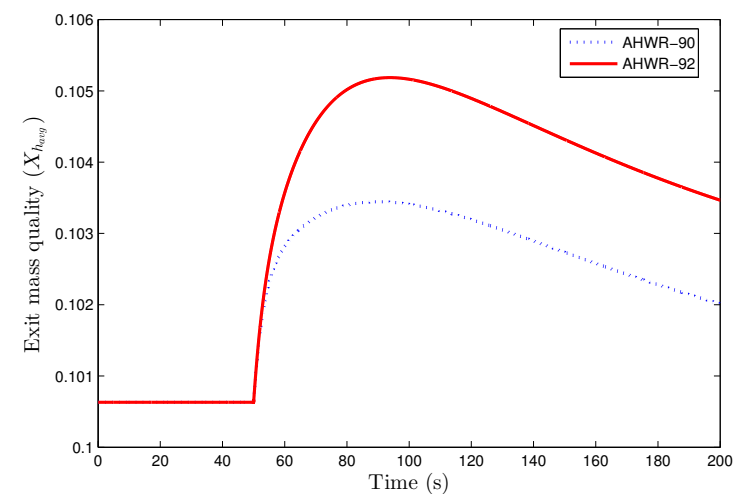

Figure 3. Exit Mass Quality Comparision

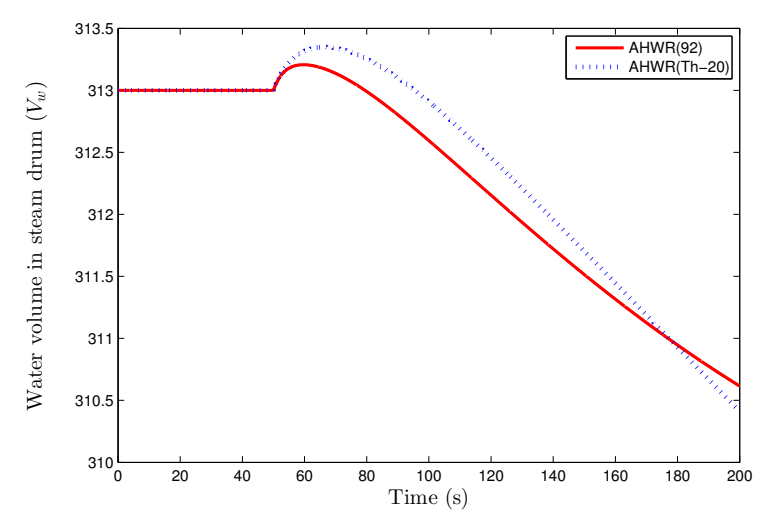

Figure 4. Effect of coupling on Thermal Hydraulic model

of coupling between the neutronic and thermal hydraulic models on the pressure, water volume and exit mass quality dynamics are depicted by the figures $4,5,6$. The increase in exit mass quality causes the reactivity associated with the void coefficient to go up, thereby lowering the reactor power. The drop in pressure is compounded by increase in steam uptake rate as well as drop in the reactor power and hence it falls faster. Reduction in reactor power leads to a fall in quantity of steam produced thus

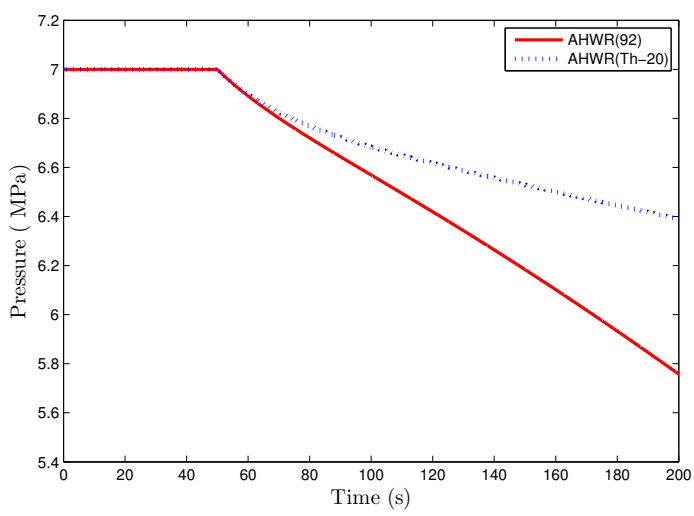

Figure 5. Effect of coupling on Thermal Hydraulic model

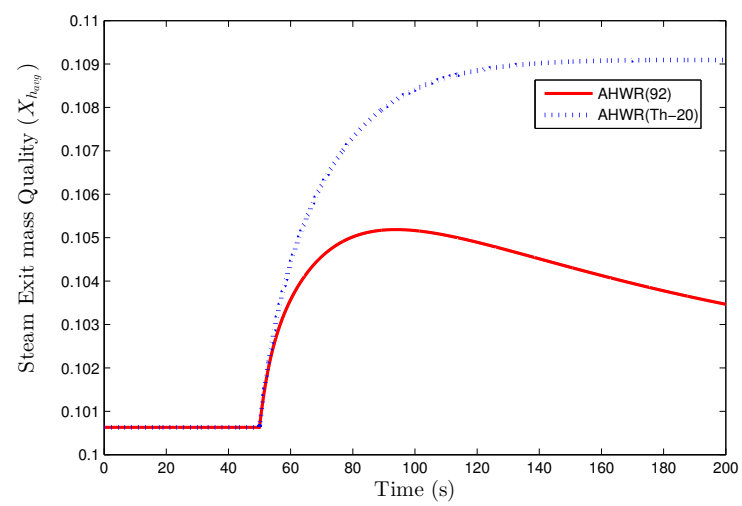

Figure 6. Effect of coupling on Thermal Hydraulic model

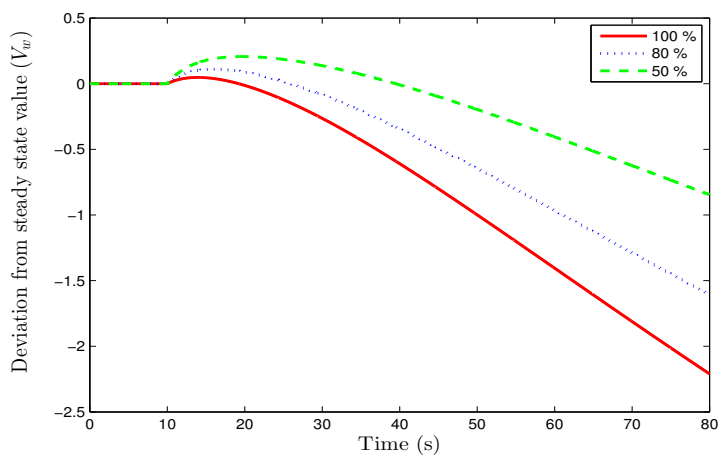

Figure 7. Effect of $10 \%$ step increase in steam flow

causing the exit mass quality to fall gradually after an initial increase corresponding to increased boiling due to fall of pressure. The initial increase in water volume followed by decrease is an example of an inverse response and attributable to the change of exit mass quality due to change of pressure. Figures 7, 8, 9 and 10 capture the model responses at reactor power levels corresponding to $50 \%$, $80 \%$ and $100 \%$ of full power to step changes of $10 \%$ in steam uptake rate. Shrink and swell dynamics caused by the change in exit mass quality are seen to be more pro- 


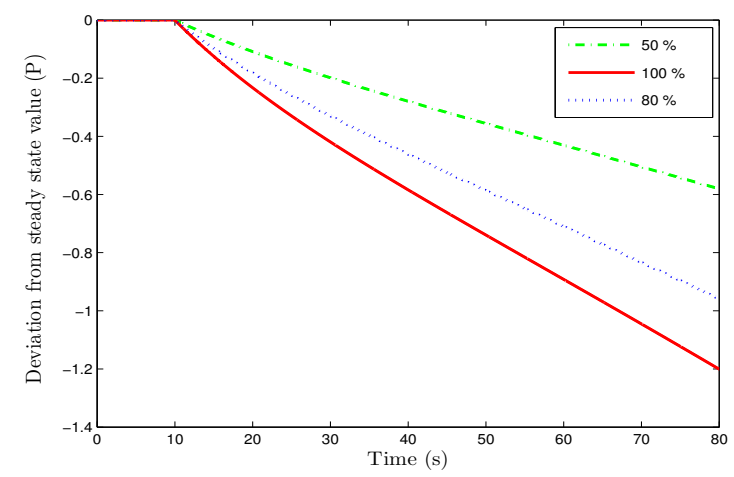

Figure 8. Effect of $10 \%$ step increase in steam flow

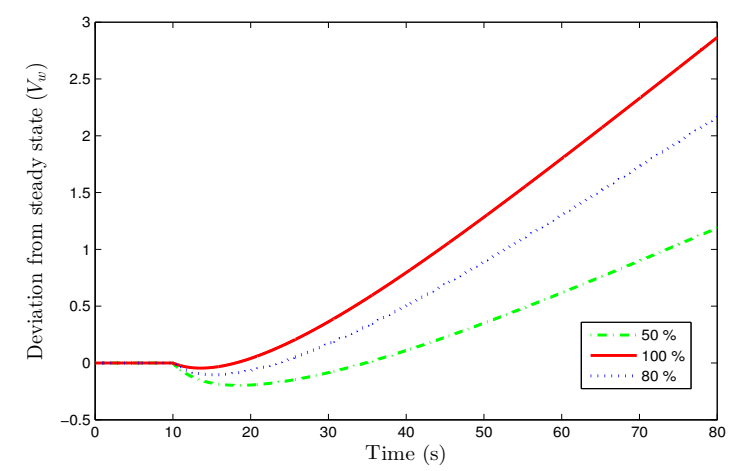

Figure 9. Effect of 10\% step decrease in steam flow

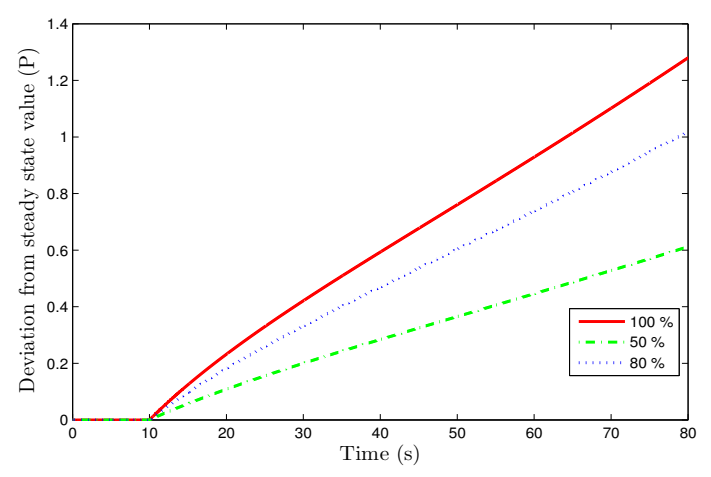

Figure 10. Effect of $10 \%$ step decrease in steam flow

nounced at low loads which is in accordance with [8] and [10]. Fig 11 and 12 represent the change of pressure and water volume at $50 \%$ reactor power to a step change in steam flow rate and offer a qualitative comparision with boiler model responses in [8] and [10].

Comparisions of the $20^{\text {th }}$ order Thermal hydraulic model have been made with the Drum boiler models proposed by Astrom and Sairam. While Astrom had proposed the mathematical model for a generalised Drum boiler, Sairam had adapted it to the AHWR. The nodal neutronics model proposed by Shimjith. et al., currently accepted as

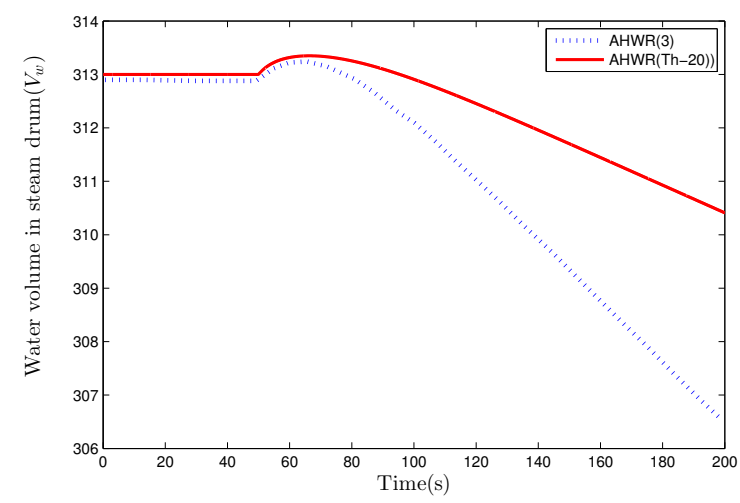

Figure 11. Comparision with other thermal hydraulic models

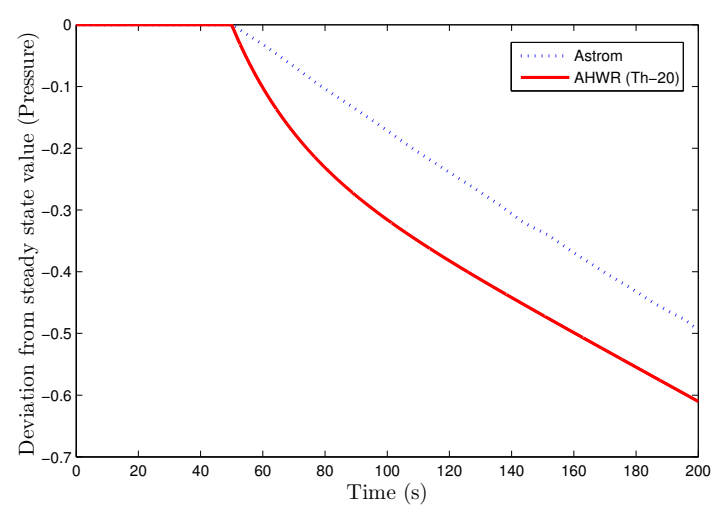

Figure 12. Comparision with other thermal hydraulic models

the standard model of AHWR for control studies, has been simulated here with the removal of simplifying assumptions of constant Pressure and Water volume. Though the trends are identical, mismatch between the model response and references are attributable to the difference in the modelling assumptions which are enumerated below.

1. The third order thermal hydraulic model assumes feedwater enthalpy to be a function of input power while the twentieth order model assumes downcomer flow rate to be a function of input power. Since input power is held constant the downcomer flow rate also gets fixed.This accounts for the difference in the water volume transients.

2. The momentum balance equations for capturing pressure dynamics in the third order model have been replaced with the assumption that pressure varies uniformly throughout the system in the twentieth order thermal hydraulic model for the sake of simplicity.

3. The division of the neutronic core into 17 nodes dicretizes the exit mass quality.

4. The downcomer flowrate is assumed to be a function of nodal power and downcomer enthalpy is com- 
puted as an additional state variable in the present model.

\section{Conclusions}

The modelling of the Advanced Heavy Water reactor is more involved because the application of nodal methods dictate the requirement of division of the reactor core into 17 nodes. The thermal hydraulic parameters associated with the nodes also need to be monitored for devising effective control strategies. The assumption of pressure and water volume transients being zero imposes additional constraints on the model. The inclusion of pressure and water volume as additional state variables allows the advantages of more comprehensive modelling of exit mass quality thereby justying the increase in model complexity. Any practical controller would be based on a model capable of handling pressure and water volume transients. The dynamics associated with the pressure and water volume transients were modelled alongwith the steam table generating algorithms and the capabilities of the non linear model explored. The model was tested for responses to changing inputs in the form of steam flow rate and a qualitative parallel was drawn between the AHWR and the standard Drum boiler model responses as reported in Literature.Since the pressure and water volume transients are captured successfully the model qualifies as an extension to the accepted model for control studies of AHWR. Future work could be directed at linearising this model after which it can be investigated for suitable control strategies.

\section{References}

1. A.Kakodkar, Design and development of the AHWRThe Indian Thorium fuelled Innovative Reactor. Nuc. Engg and Design, Vol.236(7), 683, (2006).

2. S.R.Shimjith, A.P.Tiwari, B.Bandopadhyay, Coupled Neutronics- thermal hydraulics model of Advanced Heavy Water Reactor for Control Systems studies. India Conference, 2008, INDICON 2008, Annual IEEE, Vol.1, 126, (2008).

3. S.R.Shimjith, A.P.Tiwari, M.Naskar, B.Bandyopadhyay, Space Time Kinetics Modelling of Advanced Heavy Water Reactor. An. of Nuc. Energy Vol 37 (2010)

4. S. R. Shimjith, A. P. Tiwari, B. Bandyopadhyay and R. K. Patil, Spatial Stabilization of Advanced Heavy Water Reactor. An. of Nuc. Energy, Vol-38, 1545, (2011).

5. , Modeling and Control of a Large Nuclear Reactor A Three-Time-Scale Approach Lecture Notes in Con- trol and Information Sciences, Springer Pub., Series 431.

6. T.M.Sutton, B.N.Aviles, Diffusion theory methods for spatial kinetics calculations Prog. in Nuc. Energy 30(2),(1996)

7. A.P.Tiwari, Modelling and Control of a Large Pressurized Heavy Water Reactor PhD Thesis, IIT Bombay

8. K.J.Astrom, R.D.Bell, Drum Boiler Dynamics. Automatica, Vol.36, 363, (2000).

9. K.N.V.Sairam, Design of AHWR Steam Drum Level Control System. M.Tech Dissertation, Bhabha Atomic Research Centre.

10. K.N.V.Sairam, T.U.Bhatt, A.P.Tiwari Gain Scheduled Steam Drum Level Controller for Advanced Heavy Water Reactor. IEEE Int. Conf. on Control App. (CCA), Hyd., India, August (2013).

11. S.R.Shimjith, A.P.Tiwari, B.Bandyopadhyay and R.K.Patil, A Three-Time-Scale Approach for Design of Linear State Regulator for Spatial Control of Advanced Heavy Water Reactor. IEEE Tran. of Nuc. Sc., Vol 58, No.3, June (2011).

12. S.R.Shimjith, A.P.Tiwari, B.Bandyopadhyay and R.K.Patil, Design of Fast Output Sampling Controller for Three Time Scale Systems: Application to Spatial Control of Advanced Heavy Water Reactor. IEEE Tran. of Nuc. Sc., Vol 58, No.6, June (2011).

13. R.K.Munje, B.M.Patre, S.R.Shimjith, A.P.Tiwari, Sliding Mode Control for Spatial Stabilization of Advanced Heavy Water Reactor. IEEE Tran. of Nuc. Sc., vol.60,No.4, August (2013).

14. R.K.Munje, B.M.Patre, A.P.Tiwari, Periodic Output Feedback for Spatial Control of AHWR: A Three Time Scale Approach. IEEE Tran. of Nuc. Sc., vol.61,No.4, August (2014).

15. A.Rajashekhar, A.P.Tiwari, Madhu N.Belur, Application of model order reduction techniques to space time kinetics model of AHWR . Int. Conf. on Ind. Instrum. and Control(ICIC) College of Engg. ,Pune, India, May (2015).

16. Wm.J.Garland, B.J.Hand, Simplified functions for the fast Approximations of Light Water Thermodynamic Properties. Nuc. Engg. and Design, Vol.113, 21, (1989).

17. Wm.J.Garland, R.J.Wilson, J.Bartak, J.Cizek, M.Stasny, I.Zentrich, Extensions to the approximate functions for the fast calculations of saturated water properties. Nuc Engg. and Design, Vol.136(3), 381, (1992). 